\title{
Case Study in Interdisciplinary Scientific Communication: A Decade of the INDECS Journal
}

\author{
Josip Stepanić \\ Faculty of Mechanical Engineering and Naval Architecture, Department of \\ Quality, Zagreb, Croatia \\ Jovana Zoroja \\ Faculty of Economics and Business, University of Zagreb, Croatia \\ Vanja Šimičević \\ Center for Croatian Studies, University of Zagreb, Croatia
}

\section{Abstract}

Background: Interdisciplinary scientific areas regularly develop unique methodologies, yet utilise the conventional communication modes to disseminate results of their researches. Objectives: This paper analyses whether a novel, interdisciplinary communication mode can be found in a gradually developing interdisciplinary journal. Methods/Approach: The content of the journal was categorised based on the characteristics attributed to the published papers. Statistical tests were performed to check for the overlapping categories. Results: A number of indicators, related to papers or to their authors, are introduced and quantified. Conclusions: Methodology utilised and data collected serve, on the one hand, as a referent set for treating the content of other interdisciplinary or disciplinary scientific journals, and, on the other hand, as a set for comparison and extraction of universalities or specificities of the journals. Fluctuations accompanying a gradual rise of the considered journal content prevent a definite answer to the question whether there are some emerging interdisciplinary communication novelties.

Keywords: interdisciplinary journal, communication, text mining JEL classification: D83

Paper type: Research article

Received: Nov 09, 2016

Accepted: Aug 05, 2017

Citation: Stepanić, J., Zoroja, J., Šimičević, V. (2017), "Case Study in Interdisciplinary Scientific Communication: A Decade of the INDECS Journal", Business Systems Research, Vol. 8, No. 2, pp. 101-114.

DOI: 10.1515/bsrj-2017-0019

Acknowledgments: This work has been supported by the Croatian Science Foundation under the project number IP-2014-09-6963. 


\section{Introduction}

Scholarly publishing is regular yet prevalently ubiquitous process accompanying innovations, development of scientific theories, methods and overall achievements. That very fact makes opportune, first to try to extract and eventually quantify the contribution of scientific journals, as a part of dissemination of research results and of scholarly publishing, to emerging scientific models, methods and results. Secondly, since there is a large number of scientific journals it would be interesting to analyse whether there are regularities in "scientific journal life", that is in the way how scientific journals are initiated, published, modified, extinct, etc. One can argue that the contribution of the scientific journals is the greatest in interdisciplinary fields, since other ways of scholarly related dissemination of ideas (e.g. formal education, professional societies) are represented below average or do not exist for such areas.

Regarding stated points, initial steps toward stated, rather general approaches to interdisciplinary scientific journals (ISJ) and to development of scientific ideas, are collections of corresponding results, such as Butzer (2009) and Kirchler and Hölzl (2006), to list recent ISJ analyses that cover first 35 and 25 years, respectively. Butzer (2009) notes gradual development of quantitative and qualitative indicators of the journals, as well as unique changes induced by the change of covered interdisciplinary scientific discipline. Along with specifics of the discipline, the author notes that some general, contemporary problems in science are represented in that journal, such as is a validity of peer-reviews. Kirchler and Hölzl (2006) state that the journal they analysed clearly contributed to the development of the corresponding interdisciplinary discipline. In listed sources, the content analysis was adopted. That method is not specific to extracting the interdisciplinarity, such as is the entropybased measurement of diversity (Silva et al., 2013). Before proceeding, it is in order to note that importance of interdisciplinarity is seen not just in scientific publishing but also in professional and other disciplines since interdisciplinary research essentially causes innovations (Thorleuchter and Van den Poel, 2016).

Journal Interdisciplinary Description of Complex Systems - INDECS is a scientific journal. There is online and printed edition of the journal (during first several years also the CD-ROM edition was published). The first year of publishing was 2003 with one issue, from 2004 to 2011 the journal was published two times per year and starting from 2013 INDECS is published four times per year, in January, April, July and October. INDECS is indexed in several scientific data base such as: EBSCO Academic SearchTM Complete, EconLit and Ulrich's and IndexCopernicus.

We have searched Hrčak for the Croatian journals which are represented in more than ten areas. Table 1 presents Croatian journals from Hrčak base according to number of scientific areas. We can conclude that the highest number of the journals is oriented only from one to five research areas. There are 54 journals which are oriented only to one research area and 132 journals oriented toward 2 research areas. Only one journal covers 55 research areas.

We found 17 journals which are represented in 10 or more areas, and among them is INDECS. Interdisciplinary Description of Complex Systems is the only journal which starts publishing in 21 st century and which is cited in several scientific databases. Only journals which were published in 1985 and earlier are cited in relevant scientific database. Other journals which were published in 21 st century, with two exceptions (1952 - Anali Zavoda za povijesne znanosti Hrvatske akademije znanosti i umjetnosti u Dubrovniku and 1981 - Anali Zavoda za znanstveni i umjetnički rad $u$ Osijeku) have not yet been cited in scientific database.

The goal of the paper is to investigate the dynamics and interdisciplinary scope of publications. 
Table 1

Croatian journals in base Hrčak according to number of scientific areas

\begin{tabular}{ccc}
\hline Number of areas & Number of Croatian journal & $\%$ \\
\hline 1 & 54 & $15.61 \%$ \\
\hline 2 & 132 & $38.15 \%$ \\
3 & 46 & $13.29 \%$ \\
\hline 4 & 33 & $9.54 \%$ \\
5 & 16 & $4.62 \%$ \\
\hline 6 & 21 & $6.07 \%$ \\
\hline 7 & 12 & $3.47 \%$ \\
\hline 8 & 6 & $1.73 \%$ \\
\hline 9 & 9 & $2.60 \%$ \\
\hline 10 & 8 & $2.31 \%$ \\
\hline 11 & 3 & $0.87 \%$ \\
\hline 13 & 1 & $0.29 \%$ \\
\hline 14 & 2 & $0.58 \%$ \\
\hline 20 & 1 & $0.29 \%$ \\
\hline 31 & 1 & $0.29 \%$ \\
\hline 55 & 1 & $0.29 \%$ \\
\hline Total & 346 & $100 \%$ \\
\hline
\end{tabular}

Source: Authors' survey; October, 2014

The paper consists of four parts and has following structure. After Introduction, methodology and data are defined. Results are presented in the third section with several subsections related to author and paper analysis, review process analysis, indexation and topics analysis of the selected papers. The last, four part, concludes the paper.

\section{Methodology}

In order to take a look to the past 10 years of INDECS, we have made several analyses to get a bibliometric review of ten year publishing an INDECS journal. Data are collected through web page of the journal during the last ten years (2003-2013). We investigated published volumes and issues and classify them through number of issue by volume, number of pages by volume and by issues, number of authors, affiliation of the authors, categorization of the papers, and length of the review. Text mining was also used for the topic analysis, in order to detect if titles of the paper reflect the interdisciplinary systems focus of the journal. Text mining methodology of titles was used to identify the topics that mostly appeared (Yoon and Park, 2004). There are different approaches like filtering, lemmatization or stemming which can be used. In our research we used Statistica Text Mining software focused on stemming method. Stemming method implied removing "ing" from verbs and "s" from nouns, in order to build stems which could have similar or equal meaning. Program named Statistica Text Mining uses singular value decomposition algorithm in order to handle the usually very large input matrices. The advantages of this method is that offer accurate values for relatively large singular values while disadvantage present lower accuracy on small singular values. Scree plot can be used to select the number of singular values which are useful for subsequent analysis. 


\section{Results}

\section{Paper analysis: Timeline and type of paper}

Table 2 presents an average number of issued papers by each year. According to the data in Table 2 number of issues by volume, number of papers by volume, number of pages by volume is increasing every year. The first volume, published in 2003, had only one issue and six papers. From 2004 to 2011 the journal was published two times per year and starting from 2013 INDECS is published four times per year which means that there is higher number of papers by volume and higher number of pages by volume. Average number of papers by volume difference is statistically significant at $10 \%(F=1.461, p$-value $=0.093)$ and the average number of pages difference by paper is statistically significant at $10 \%(F=1.866, p$-value $=0.052)$.

Table 2

Average number of issued papers by year

\begin{tabular}{|c|c|c|c|c|c|c|c|}
\hline $\begin{array}{c}\text { Year of } \\
\text { publishing }\end{array}$ & Vol. & $\begin{array}{c}\text { \# of issues } \\
\text { by vol. }\end{array}$ & $\begin{array}{c}\text { \#r of } \\
\text { papers by } \\
\text { vol. }\end{array}$ & $\begin{array}{l}\text { Avg. \#of } \\
\text { papers by } \\
\text { vol. }\end{array}$ & $\begin{array}{c}\text { \# of pages } \\
\text { by vol. }\end{array}$ & $\begin{array}{c}\text { Avg. \#of } \\
\text { pages by vol. }\end{array}$ & $\begin{array}{l}\text { Avg. \# of } \\
\text { pages by } \\
\text { paper }\end{array}$ \\
\hline 2003 & 1 & 1 & 6 & 6 & 65 & 65 & 10.8 \\
\hline 2004 & 2 & 2 & 14 & 7 & 143 & 71.5 & 10.2 \\
\hline 2005 & 3 & 2 & 10 & 5 & 108 & 54 & 10.8 \\
\hline 2006 & 4 & 2 & 12 & 6 & 151 & 75.5 & 12.6 \\
\hline 2007 & 5 & 2 & 11 & 5.5 & 160 & 80 & 14.5 \\
\hline 2008 & 6 & 2 & 12 & 6 & 131 & 65.5 & 10.9 \\
\hline 2009 & 7 & 2 & 10 & 5 & 116 & 58 & 11.6 \\
\hline 2010 & 8 & 2 & 11 & 5.5 & 147 & 73.5 & 13.4 \\
\hline 2011 & 9 & 2 & 9 & 4.5 & 160 & 80 & 17.8 \\
\hline 2012 & 10 & 3 & 22 & 7.33 & 297 & 99 & 13.5 \\
\hline 2013 & 11 & 4 & 37 & 9.2 & 445 & 111.25 & 12.0 \\
\hline Total & 66 & 24 & 154 & 67.03 & 1923 & 833.25 & 12.5 \\
\hline
\end{tabular}

Source: Authors' survey; October, 2014

Papers published in INDECS journal can be categorized into four groups: preliminary report, conference paper, regular paper and review (Table 3). Most of the papers through last ten years were classified as regular paper. Only 13 papers (7 in 2005 and 6 in 2006) were classified as preliminary report. There were only 4 reviews in 2005, 2012 and 2013. In each year there were several regular papers. Chi-square indicated these differences are statistically significant by $1 \%$ (chi-square $=117.767$; $\mathrm{p}$-value $=0.000$ ).

Table 3

Categorization of the papers

\begin{tabular}{ccccccc}
\hline Year & Volume & $\begin{array}{c}\text { Number of papers by } \\
\text { volume }\end{array}$ & $\begin{array}{c}\text { Preliminary } \\
\text { report }\end{array}$ & $\begin{array}{c}\text { Conference } \\
\text { paper }\end{array}$ & $\begin{array}{c}\text { Regular } \\
\text { paper }\end{array}$ & Review \\
\hline 2003 & 1 & 6 & 0 & 0 & 6 & 0 \\
2004 & 2 & 14 & 2 & 10 & 1 & 1 \\
2005 & 3 & 10 & 0 & 7 & 3 & 0 \\
2006 & 4 & 12 & 0 & 7 & 5 & 0 \\
2007 & 5 & 11 & 0 & 3 & 8 & 0 \\
2008 & 6 & 12 & 0 & 3 & 9 & 0 \\
2009 & 7 & 10 & 0 & 0 & 10 & 0 \\
2010 & 8 & 11 & 0 & 0 & 11 & 0 \\
2011 & 9 & 9 & 0 & 0 & 9 & 0 \\
2012 & 10 & 22 & 0 & 0 & 21 & 1 \\
2013 & 11 & 37 & 2 & 0 & 35 & 2 \\
Total & 11 & 154 & 30 & 118 & 4 \\
\hline
\end{tabular}

Source: Authors' survey; October, 2014 


\section{Author analysis}

Let us analyse the relation between the paper category and the number of authors. Most of the papers, no matter the categorization type, were written by three authors. Preliminary reports are mostly written by one author. Average number of authors is almost the same for the conference (1.8) and regular paper (2.0) while the mean for the preliminary report and review is lower (1.2). Chi-square indicated that observed differences are not statistically significant (chi-square $=6.207 ; p$-value $=0.719$ ).

The average number of authors is approximately 1.7 with the lowest standard deviation of 0.5 for the review category. The highest number of authors is for the category regular paper (128), while in category review there are only four authors and for the conference paper only nine authors. In order to determine are there statistically significant differences for average values of category of the paper and number of authors we made variance analysis. Conducted analysis showed that differences in average values for number of authors and category of the paper are not statistically significant $(F=0.510$; $p$-value $=0.676)$.

Table 4

Descriptive statistics for number of authors

\begin{tabular}{|c|c|c|c|c|c|}
\hline \multirow[t]{2}{*}{$\begin{array}{l}\text { Category of the } \\
\text { paper }\end{array}$} & \multirow[t]{2}{*}{$\begin{array}{l}\text { \# of } \\
\text { authors }\end{array}$} & \multirow[t]{2}{*}{$\begin{array}{l}\text { Avg. \# of } \\
\text { authors }\end{array}$} & \multirow[t]{2}{*}{ Std. dev. } & \multicolumn{2}{|c|}{$\begin{array}{c}\text { Confidence interval of estimation } \\
\text { of average number of authors by } \\
\text { paper category ( } 95 \%)\end{array}$} \\
\hline & & & & Lower value & Upper value \\
\hline Preliminary report & 13 & 1.85 & 1.281 & 1.07 & 2.62 \\
\hline Conference paper & 9 & 1.56 & 0.882 & 0.88 & 2.23 \\
\hline Regular paper & 128 & 1.60 & 0.881 & 1.45 & 1.76 \\
\hline Review & 4 & 1.25 & 0.500 & 0.45 & 2.05 \\
\hline Total & 154 & 1.61 & 0.910 & 1.47 & 1.76 \\
\hline
\end{tabular}

Source: Authors' survey; October, 2014

Table 5 presents number of authors by year issued and by continent. In 2003, when the journal was launched, there were only authors from the Europe and through the next year's number of authors from other continents increased. Approximately the same number of authors was in 2008 (30) and in 2012 (32). The only difference is that in 2012 authors from all over the world except from South America have written for the journal and in 2008 there were only authors from Asia, Europe and North America.

Table 5

Number of authors by year issued and continent

\begin{tabular}{|c|c|c|c|c|c|c|c|c|c|c|c|c|}
\hline \multirow[t]{2}{*}{ Country } & \multicolumn{11}{|c|}{ Year } & \multirow[t]{2}{*}{ Total } \\
\hline & 2003 & 2004 & 2005 & 2006 & 2007 & 2008 & 2009 & 2010 & 2011 & 2012 & 2013 & \\
\hline Africa & 0 & 0 & 0 & 0 & 0 & 0 & 0 & 1 & 0 & 1 & 0 & 2 \\
\hline Australia & 0 & 0 & 1 & 2 & 1 & 0 & 0 & 0 & 0 & 1 & 1 & 6 \\
\hline Asia & 0 & 4 & 3 & 7 & 1 & 2 & 1 & 4 & 1 & 4 & 3 & 30 \\
\hline Europe & 12 & 12 & 10 & 13 & 13 & 19 & 10 & 12 & 9 & 22 & 50 & 182 \\
\hline South America & 0 & 0 & 0 & 0 & 0 & 0 & 1 & 0 & 1 & 0 & 0 & 2 \\
\hline North America & 0 & 2 & 0 & 2 & 4 & 1 & 0 & 1 & 0 & 2 & 1 & 13 \\
\hline Total & 12 & 18 & 14 & 24 & 19 & 32 & 12 & 18 & 11 & 30 & 55 & 235 \\
\hline
\end{tabular}

Source: Authors' survey; October, 2014 


\section{Review process analysis}

Table 6 provides information about duration of review process in days. That duration we calculate as difference in dates of accepting and receiving the manuscript. In 2003 , there was only one volume with six papers and the average duration for the review process was 28.17. It is interesting to compare 2012 and 2013. In 2012 there were 22 papers and average number of days was 119.55, while in 2013 the average number of days was 73.86 for the 37 papers. In order to determine are there statistically significant differences for number of review days and for the number of papers we made variance analysis. Conducted analysis showed that there is statistically significant difference at $1 \%$ for number of review days and the number of papers $(F=4.626 ; p$-value $=0.000)$.

Table 6

Number of review days by year

\begin{tabular}{ccccc}
\hline Year & Volume & $\begin{array}{c}\text { Number of } \\
\text { papers }\end{array}$ & $\begin{array}{c}\text { Average duration of the } \\
\text { review process in days }\end{array}$ & $\begin{array}{c}\text { Std. deviation } \\
\text { in days }\end{array}$ \\
\hline $\mathbf{2 0 0 3}$ & 1 & 6 & 28.17 & 10.815 \\
$\mathbf{2 0 0 4}$ & 2 & 14 & 71.14 & 33.709 \\
$\mathbf{2 0 0 5}$ & 3 & 10 & 38.60 & 37.974 \\
$\mathbf{2 0 0 6}$ & 4 & 12 & 120.75 & 63.090 \\
$\mathbf{2 0 0 7}$ & 5 & 11 & 136.82 & 68.331 \\
$\mathbf{2 0 0 8}$ & 6 & 12 & 285.33 & 357.307 \\
$\mathbf{2 0 0 9}$ & 7 & 10 & 60.10 & 71.177 \\
$\mathbf{2 0 1 0}$ & 8 & 11 & 176.91 & 92.302 \\
\hline $\mathbf{2 0 1 1}$ & 9 & 9 & 248.33 & 186.692 \\
$\mathbf{2 0 1 2}$ & 10 & 22 & 119.55 & 117.099 \\
$\mathbf{2 0 1 3}$ & 11 & 37 & 73.86 & 72.026 \\
\hline Total & 11 & 154 & 117.36 & 144.311 \\
\hline SOUrCe
\end{tabular}

Source: Authors' survey; October, 2014

\section{Indexation analysis}

Classification of the papers published in INDECS journal is defined by the authors in accordance with the instructions. According to Table 7 all papers are classified by JEL classification (154) and some also by other classifications such as are ACM, PACS and APA. Besides JEL, there is a large number of papers classified by PACS (71).

Table 7

Number of papers by categorization

\begin{tabular}{lcc}
\hline Categorization & Number of papers & $\%$ \\
\hline ACM & 25 & $16 \%$ \\
JEL & 154 & $100 \%$ \\
PACS & 71 & $46 \%$ \\
APA & 38 & $25 \%$ \\
\hline
\end{tabular}

Source: Authors' survey; October, 2014

Table 8 presents the number of papers having the ACM classification. In the first 10 volumes there are 38 papers having ACM classification. The highest number of papers is grouped in J.4 (10), which means Social and Behavioural Sciences. The lowest number of papers, only one, is found in the following subgroups: H.O, H.1, H.4 and J.8. Other subcategories are represented by two papers: D.1, D.2, G.3, G.4, H.5 and K.4. 
Table 8

ACM categorization

\begin{tabular}{lc}
\hline ACM category & Frequency \\
\hline D.1 & 2 \\
D.2 & 2 \\
G.3 & 2 \\
G.4 & 2 \\
H.0 & 1 \\
H.1 & 1 \\
H.4 & 1 \\
H.5 & 2 \\
I.2 & 5 \\
I.6 & 4 \\
J.2 & 3 \\
\hline J.4 & 10 \\
J.8 & 1 \\
K.4 & 2 \\
Total & 38 \\
\hline Source & Authors sUrVEy. Octo \\
\hline
\end{tabular}

Source: Authors' survey; October, 2014

Note: $D=S o f t w a r e, G=$ Mathematics of Computing, $H=$ Information Systems, I=Computing Methodologies, $\mathrm{J}=$ Computer Applications, $\mathrm{K}=$ Computing Milieux.

Table 9 presents the number of papers classified by JEL categorization according to the first categorization. In the first 10 years there are 154 papers which are classified by JEL classification, altogether in 330 categories. In most cases authors used classification group $D$, which is related to Microeconomics topics. The smaller number of papers is grouped in following subgroups: $\mathrm{H}-$ Public economics, $\mathrm{N}-$ Economic History and $\mathrm{F}$ - International economics.

Table 9

JEL categorization

\begin{tabular}{|c|c|}
\hline JEL categorization & Frequency \\
\hline A - General Economics and Teaching & 10 \\
\hline B - History of Economic Thought, Methodology, and Heterodox Approaches & 10 \\
\hline C - Mathematical and Quantitative Methods & 32 \\
\hline D - Microeconomics & 88 \\
\hline E - Macroeconomics and Monetary Economics & 11 \\
\hline F - International Economics & 6 \\
\hline H - Public Economics & 3 \\
\hline I - Health, Education, and Welfare & 15 \\
\hline J - Labor and Demographic Economics & 10 \\
\hline L - Industrial Organization & 13 \\
\hline M - Business Administration and Business Economics • Marketing • Accounting & 9 \\
\hline N - Economic History & 4 \\
\hline O - Economic Development, Technological Change, and Growth & 35 \\
\hline P - Economic Systems & 10 \\
\hline $\begin{array}{l}\text { Q - Agricultural and Natural Resource Economics • Environmental and } \\
\text { Ecological Economics }\end{array}$ & 21 \\
\hline R - Urban, Rural, Regional, Real Estate, and Transportation Economics & 10 \\
\hline Y - Miscellaneous Categories & 19 \\
\hline Z - Other Special Topics & 24 \\
\hline Total & 330 \\
\hline
\end{tabular}

Source: Authors' survey; October, 2014

Note: Total of 154 papers are classified in 330 categories, since most of the papers mention more than one JEL category. 
Table 10 presents the number of papers classified by PACS categorization. In the analysed 10 years there are 71 papers which are classified by PACS classification but some of them used more than one PACS category. In most cases authors used classification group 80, which means Interdisciplinary Physics and Related Areas of Science and Technology. The lower number of papers is grouped in following subgroups: 28 - Nuclear Engineering and Nucelar Power Studies, 43 - Acoustics, 51 Physics of Gases.

Table 10

PACS categorization

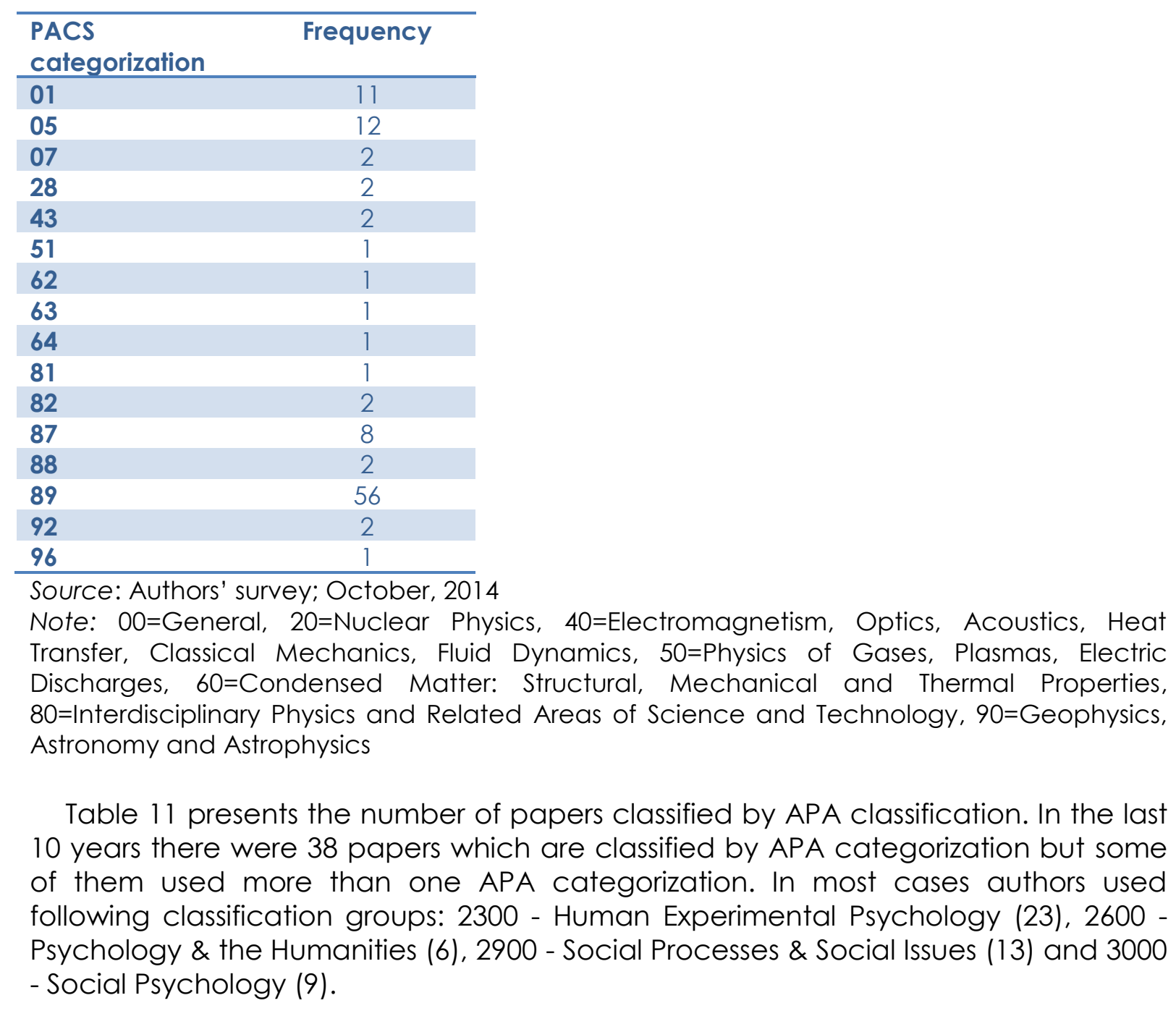


Table 11

APA classification

\begin{tabular}{|c|c|c|}
\hline APA classification & $\begin{array}{l}\text { APA } \\
\text { sub-classification }\end{array}$ & Frequency \\
\hline \multirow{2}{*}{2200 - Psychometrics \& Statistics \& Methodology } & 2240 & 1 \\
\hline & 2260 & 1 \\
\hline \multirow{6}{*}{2300 - Human Experimental Psychology } & 2300 & 1 \\
\hline & 2320 & 1 \\
\hline & 2326 & 1 \\
\hline & 2340 & 11 \\
\hline & 2360 & 1 \\
\hline & 2380 & 8 \\
\hline 2400 - Animal Experimental \& Comparative Psychology & 2400 & 1 \\
\hline \multirow{2}{*}{2500 - Physiological Psychology \& Neuroscience } & 2510 & 1 \\
\hline & 2520 & 1 \\
\hline 2600 - Psychology \& the Humanities & 2630 & 6 \\
\hline 2700 - Communication Systems & 2700 & 1 \\
\hline \multirow[t]{2}{*}{2800 - Developmental Psychology } & 2820 & 1 \\
\hline & 2840 & 1 \\
\hline \multirow[t]{5}{*}{2900 - Social Processes \& Social Issues } & 2910 & 6 \\
\hline & 2920 & 1 \\
\hline & 2930 & 1 \\
\hline & 2960 & 4 \\
\hline & 2990 & 1 \\
\hline \multirow[t]{2}{*}{3000 - Social Psychology } & 3020 & 3 \\
\hline & 3040 & 6 \\
\hline 3100 - Personality Psychology & 3100 & 1 \\
\hline 3200 - Psychological \& Physical Disorders & 3260 & 1 \\
\hline 3500 - Educational Psychology & 3510 & 1 \\
\hline \multirow[t]{3}{*}{4000 - Engineering \& Environmental Psychology } & 4010 & 5 \\
\hline & 4050 & 1 \\
\hline & 4070 & 1 \\
\hline \multirow[t]{3}{*}{4100 - Intelligent systems } & 4100 & 2 \\
\hline & 4120 & 2 \\
\hline & & 73 \\
\hline
\end{tabular}

Source: Authors' survey; October, 2014

Table 12 provides number of papers grouped by one of four categorization systems (ACM, JEL, PACS and APA). All papers published in the last ten years have at least one JEL classification, while other categorization it is not represented in all papers. The first volume had six papers and they all were classified by JEL and PACS classification and only four of them were classified by APA and ACM classification. In some volumes, such as volume 6, 7, 8, 9, APA and PACS classification were not represented at all. In the last, 11 th volume, 37 papers were published and all of them were classified by JEL, 14 and 13 papers were classified by PACS and APA and only 2 papers were classified by ACM classification. 
Table 12

Number of papers by classification

\begin{tabular}{|c|c|c|c|c|c|c|c|c|c|}
\hline \multirow[t]{2}{*}{ Volume } & \multirow{2}{*}{$\begin{array}{c}\text { Number of papers by } \\
\text { volume }\end{array}$} & \multicolumn{2}{|c|}{ ACM } & \multicolumn{2}{|c|}{ JEL } & \multicolumn{2}{|c|}{ PACS } & \multicolumn{2}{|c|}{ APA } \\
\hline & & $\mathrm{N}$ & $\%$ & $\mathrm{~N}$ & $\%$ & $\mathrm{~N}$ & $\%$ & $\mathrm{~N}$ & $\%$ \\
\hline 1 & 6 & 4 & $66.67 \%$ & 6 & $100 \%$ & 6 & $100.00 \%$ & 4 & $66.67 \%$ \\
\hline 2 & 14 & 5 & $35.71 \%$ & 14 & $100 \%$ & 10 & $71.43 \%$ & 5 & $35.71 \%$ \\
\hline 3 & 10 & 1 & $10.00 \%$ & 10 & $100 \%$ & 9 & $90.00 \%$ & 5 & $50.00 \%$ \\
\hline 4 & 12 & 1 & $8.33 \%$ & 12 & $100 \%$ & 10 & $83.33 \%$ & 2 & $16.67 \%$ \\
\hline 5 & 11 & 2 & $18.18 \%$ & 11 & $100 \%$ & 2 & $18.18 \%$ & 1 & $9.09 \%$ \\
\hline 6 & 12 & 2 & $16.67 \%$ & 12 & $100 \%$ & 0 & $0.00 \%$ & 0 & $0.00 \%$ \\
\hline 7 & 10 & 1 & $10.00 \%$ & 10 & $100 \%$ & 0 & $0.00 \%$ & 0 & $0.00 \%$ \\
\hline 8 & 11 & 2 & $18.18 \%$ & 11 & $100 \%$ & 1 & $9.09 \%$ & 0 & $0.00 \%$ \\
\hline 9 & 9 & 1 & $11.11 \%$ & 9 & $100 \%$ & 3 & $33.33 \%$ & 0 & $0.00 \%$ \\
\hline 10 & 22 & 4 & $18.18 \%$ & 22 & $100 \%$ & 16 & $72.73 \%$ & 8 & $36.36 \%$ \\
\hline 11 & 37 & 2 & $5.41 \%$ & 37 & $100 \%$ & 14 & $37.84 \%$ & 13 & $35.14 \%$ \\
\hline Total & 154 & 25 & $16.23 \%$ & 154 & $100 \%$ & 71 & $46.10 \%$ & 38 & $24.68 \%$ \\
\hline
\end{tabular}

Source: Authors' survey; October, 2014

Topics analysis

In order to better understand topics and themes that are presented in the titles of the papers, a tag cloud analysis was conducted. The results are presented in Figure 1. The tag cloud analysis is very useful because of its simplicity and visualization of the most occurring words in selected text (de Spindler et al., 2011). In addition, most frequently used words are larger and more visible. We have used Wordle program to create a tag cloud (Feinberg, 2017).

Figure 1 presents that the stems "model", "system" and "complex" arose most often in the paper titles. In addition, there are also few other words which are highlighted: analysis, approach, decision, development, social, research, system, theory.

Figure 1

Tag cloud of the most often used words in paper titles; most frequent 50 words

adaptive (4) agent-based (4) agent (4) analysis (7) approach (7) based (5) case (3)
communication (3) competition (3) complex croatian (5) $_{\text {(5) }}$ decision dexity $_{(8)}$ countries (5) dynamics (3) economic (3) education (4) energy (5) environment (4) experience (3) globalization (5) growth $_{(5)}$ happiness (4) human $_{(6)}$ learning ${ }_{(7)}$ making $_{(8)}$ management ${ }_{(5)}$ ather is

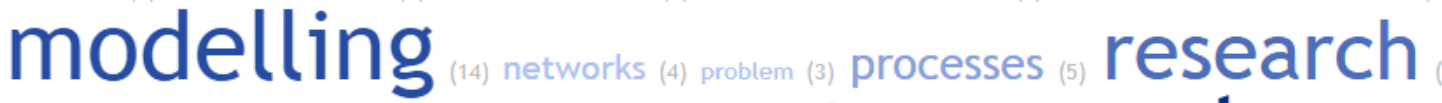

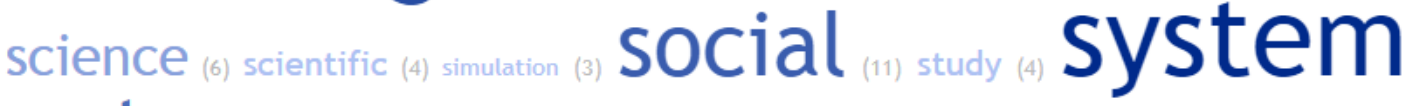
systems theory

Source: Author work, Tag Crowd 
Table 13

Most commonly used words in titles of papers; $=>4$ occurrences

\begin{tabular}{|c|c|c|c|}
\hline Stem / Phrase & Number of occurrences in the title & Number of papers & Examples \\
\hline model & 34 & 31 & \\
\hline system & 25 & 24 & \\
\hline complex & 20 & 20 & \\
\hline develop & 11 & 11 & developed \\
\hline decis & 10 & 9 & decision \\
\hline research & 10 & 10 & \\
\hline social & 10 & 10 & \\
\hline approach & 9 & 9 & \\
\hline make & 8 & 8 & making \\
\hline process & 8 & 8 & \\
\hline theori & 8 & 7 & theory \\
\hline use & 8 & 7 & \\
\hline learn & 7 & 5 & learning \\
\hline microeconom & 7 & 7 & microeconomic \\
\hline analysi & 6 & 6 & analysis \\
\hline energi & 6 & 5 & energy \\
\hline global & 6 & 6 & \\
\hline human & 6 & 6 & \\
\hline product & 6 & 6 & products \\
\hline scienc & 6 & 5 & science \\
\hline base & 5 & 5 & based \\
\hline countri & 5 & 5 & countries \\
\hline croatian & 5 & 4 & \\
\hline growth & 5 & 5 & \\
\hline manag & 5 & 5 & management \\
\hline network & 5 & 5 & \\
\hline thermodynam & 5 & 5 & thermodynamic \\
\hline adapt & 4 & 3 & adaptive \\
\hline agent & 4 & 4 & \\
\hline agent-bas & 4 & 4 & agent-based \\
\hline cognit & 4 & 4 & cognitive \\
\hline competit & 4 & 2 & competition \\
\hline distribut & 4 & 4 & distribution \\
\hline dynam & 4 & 4 & dynamics \\
\hline econom & 4 & 4 & economic \\
\hline economi & 4 & 4 & economy \\
\hline educ & 4 & 4 & education \\
\hline environ & 4 & 4 & environment \\
\hline experi & 4 & 4 & experience \\
\hline first & 4 & 4 & \\
\hline happi & 4 & 4 & happiness \\
\hline irrevers & 4 & 4 & irreversible \\
\hline measur & 4 & 4 & measure \\
\hline physic & 4 & 4 & physics \\
\hline problem & 4 & 4 & \\
\hline resourc & 4 & 4 & resource \\
\hline scientif & 4 & 4 & scientific \\
\hline simul & 4 & 4 & simulate \\
\hline studi & 4 & 4 & study \\
\hline sustain & 4 & 4 & sustainable \\
\hline team & 4 & 4 & \\
\hline toward & 4 & 4 & \\
\hline virtual & 4 & 4 & \\
\hline
\end{tabular}

Source: Author work; Statistica data miner 
In order to extract most commonly used words in titles of papers, we have conducted text mining analysis-stemming approach by Statistica Text Miner program. The results are presented in Table 13. We have examined number of occurrences of words in the title and number of papers. Following seven words are used in more than 10 titles of the papers: model, system, complex, develops, decis, research and social. However, word model is the most often word and it appeared in 31 papers with 34 occurrences in the title. Words system and complex are used in more than 20 papers. These two words (system and complex) are also part of the title of journal (Interdisciplinary Description of Complex Systems) which explains their frequent usage.

According to Cattell (1966) it is possible to plot the eigenvalues which are related with each component and look for a "break" between them. There is difference between the components that appear before and after the break. Important and meaningful components are those appeared before compared to unimportant and less meaningful components which appear after the break. Figure 2 indicates that five concepts extracted with Singular Value Decomposition are relevant.

Figure 2

Scree plot of concepts extracted with Singular Value Decomposition

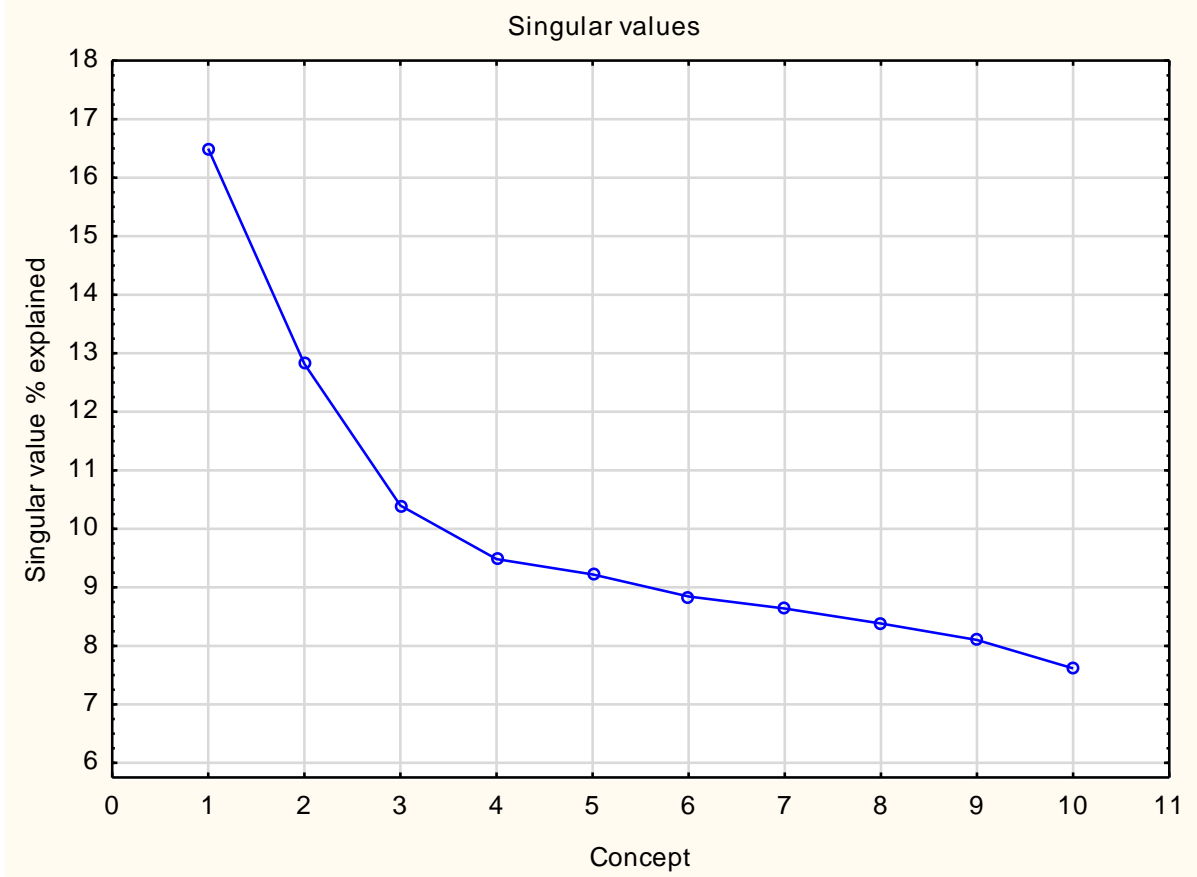

Source: Author work; Statistica data miner

Table 14 presents the most relevant five concepts (Energy, Growth, Development, Microeconomics, Croatian) extracted with Singular Value Decomposition. The first concept contains words model, system, complex, social, use, approach, energi, agent-bas, base, network. Based on the words, this concept was called Energy, since it refers to the group of papers of the energy related research. The second concept contains words model, agent-bas, agent, simul, base, growth, human, dynam, product, educ. Based on the words, this concept was called Growth, since it refers to the group of papers of the growth related research. The third concept contains words decis, make, theori, team, first, human, global, develop, learn, problem. Based on the words, this concept was called Development, since it refers to the group of papers of the development related research. The fourth concept 
contains words system, use, energi, decis, make, microeconom, analysi, social, resource, agent-bas. Based on the words, this concept was called Microeconomics, since it refers to the group of papers of the microeconomy related research. The fifth concept contains words complex, social, network, croatian, analysi, scientif, base, approach, environ, dynam. Based on the words, this concept was called Croatian, since it refers to the group of papers of the Croatian related research.

Table 14

Identification of five most frequent topics with Singular Valve Decomposition

\begin{tabular}{llllllllll}
\hline & Energy & \multicolumn{2}{c}{ Growth } & \multicolumn{2}{c}{ Development } & \multicolumn{2}{c}{ Microeconomics } & \multicolumn{2}{c}{ Croatian } \\
\hline Words & SVD & Words & SVD & Words & SVD & Words & SVD & Words & SVD \\
model & 0,1105 & model & 0,0873 & decis & 0,1660 & system & 0,0487 & complex & 0,1194 \\
system & 0,0582 & agent-bas & 0,0158 & make & 0,1304 & Use & 0,0294 & social & 0,1112 \\
complex & 0,0303 & agent & 0,0146 & theori & 0,0531 & energi & 0,0249 & network & 0,0678 \\
social & 0,0203 & simul & 0,0136 & team & 0,0248 & decis & 0,0166 & croatian & 0,0609 \\
use & 0,0184 & base & 0,0117 & first & 0,0186 & make & 0,0139 & analysi & 0,0480 \\
approach & 0,0164 & growth & 0,0079 & human & 0,0183 & microeconom & 0,0122 & scientif & 0,0340 \\
energi & 0,0134 & human & 0,0072 & global & 0,0182 & analysi & 0,0113 & base & 0,0339 \\
agent-bas & 0,0133 & dynam & 0,0062 & develop & 0,0174 & social & 0,0097 & approach & 0,0217 \\
base & 0,0133 & product & 0,0059 & learn & 0,0092 & resourc & 0,0058 & environ & 0,0216 \\
network & 0,0130 & educ & 0,0048 & problem & 0,0046 & agent-bas & 0,0057 & dynam & 0,0200 \\
\hline
\end{tabular}

Source: Author work; Statistica data miner

\section{Conclusion}

Presented and analysed data point to the fact that the journal INDECS to dissemination of scientifically founded pieces of information, related to the broad number of scientific fields. Quantitatively, both in number of issues and number of papers per volume, the journal gradually develops. Number of countries from which the authors are, follows the increase. Moreover, number of topics represented in a paper spreads through a number of different classifications and their categories and sub-categories. That contributes to the interdisciplinary character of the journal.

There are no statistically significant variations in number of authors per volume or per category of the paper. Whether there are significant differences in the number of paper per discipline (category or sub-category of some classification) cannot be stated using the available volume of papers.

However, the average time for review within one volume fluctuates significantly, so one can assume that more time is needed for some gradual effect to emerge. This represent a possible venue for improving the quality of the journal.

Results of text mining analysis implied that there are 53 words which are most commonly used. Following seven words are used in more than 10 titles: model, system, complex, develop, decis, research and social, while word model is the most often word and it appeared in 31 paper with 34 occurrences in the title. Those 53 words were grouped into five concepts: Energy, Growth, Development, Microeconomics, Croatian. These five concepts present different research areas and include papers related to diverse scientific fields, which explain interdisciplinary of INDECS journal. 


\section{References}

1. Butzer, K. (2009), "Evolution of an interdisciplinary enterprise: the Journal of Archaeological Science at 35 years", Journal of Archeological Science, Vol. 36 , No. 9, pp. 1842-1846.

2. Catell, R. B. (1966), "The Scree Test For The Number Of Factors", Multivariate Behavioral Research, Vol. 1, No. 2, pp. 245-276.

3. de Spindler, A., Leone, S., Nebeling, M., Geel, M., Norrie, M. C. (2011), "Using Synchronised Tag Clouds for Browsing Data Collections", Advanced Information Systems Engineering, Lecture Notes in Computer Science, Vol. 6741, pp. 214-228.

4. Feinberg, J. (2017), "Wordle", available at: http://www.wordle.net/ (01 September 2017).

5. Kirchler, E., Hölzl, E. (2006), "Twenty-five years of the Journal of Economic Psychology (1981-2005): A report on the development of an interdisciplinary field of research", Journal of Economic Psychology, Vol. 27, No. 6, pp. 793-804.

6. Silva, F. N., Rodrigues, F. A., de Oliveira Junior, O. N., da Fontoura Costa, L. (2013), "Quantifying the interdisciplinarity of scientific journals and fields", Journal of Informetrics, Vol. 7, No. 2, pp. 469-477.

7. Thorleucter, D., Van den Poel, D. (2016), "Identification of interdisciplinary ideas", Information Processing \& Management, Vol. 52, No. 6, pp. 1074-1085.

8. Yoon, B., Park, Y. (2004), "A text-mining-based patent network: Analytical tool for high-technology trend", The Journal of High Technology Management Research, Vol. 15, No. 1, pp. 37-50.

\section{About the authors}

Josip Stepanić earned his B.Sc. in 1994 and M.Sc. in 1998 from theoretical physics. He finished Ph.D. in 2003 from mechanical engineering, all from University of Zagreb. Currently he is Head of the Chair of Non-destructive Testing, part of Department of Quality - Faculty of Mechanical Engineering \& Naval Architecture, University of Zagreb. His researches include system science, complex adaptive systems and several specific types of systems. Author can be contacted at josip.j.stepanic@fsb.hr.

Jovana Zoroja, Ph.D. is an Assistant Professor at the Faculty of Economics and Business, University of Zagreb, Department of Informatics. She received PhD in Information Systems at the Faculty of Economics and Business Zagreb. She was also educated at the LSE - Summer School in London in the field of Business Development and ICT Innovation. Her main research interests are information and communication technology, e-learning, simulation games and simulation modelling. She is actively engaged in number of scientific projects (FP7-ICT, bilateral cooperation, national projects). Jovana Zoroja published several scientific papers in international and national journals and participated in many scientific international conferences. The author can be contacted at jzoroja@efzg.hr.

Vanja Šimičević has PhD in Economics from the University of Zagreb, Faculty of Economics and Business in the area of quantitative economics. Her major area of research is focused on applications of quantitative methods in social sciences and on those topics she published number of papers. She is Associate Professor at the University of Zagreb Centre for Croatian Studies, Head of Sociology Department, teaching Multivariate Statistical Methods, and Statistics in Social Sciences. Author can be contacted at vanja.simicevic@zg.htnet.hr. 